\title{
Australian water mass variations from GRACE data linked to Indo-Pacific climate variability
}

David García-García ${ }^{1, *}$, Caroline C. Ummenhofer ${ }^{2}$, and Victor Zlotnicki ${ }^{3}$

${ }^{1}$ Department of Applied Mathematics, EPS, University of Alicante, Spain.

${ }^{2}$ Climate Change Research Centre, University of New South Wales, Sydney, New South Wales, Australia.

${ }^{3}$ Jet Propulsion Laboratory, California Institute of Technology, Pasadena, California, USA.

\begin{abstract}
Time-Variable Gravity data from the Gravity Recovery And Climate Experiment (GRACE) mission are used to study total water content over Australia for the period 2002-2010. A time-varying annual signal explains $61 \%$ of the variance of the data, in good agreement with two independent estimates of the same quantity from hydrological models. Water mass content variations across Australia are linked to Pacific and Indian Ocean variability, associated with El Niño-Southern Oscillation (ENSO) and the Indian Ocean Dipole (IOD), respectively. From 1989, positive (negative) IOD phases were related to anomalously low (high) precipitation in southeastern Australia, associated with a reduced (enhanced) tropical moisture flux. In particular, the sustained water mass content reduction over central and

*Contact: d.garcia@ua.es
\end{abstract}


southern regions of Australia during the period 2006-2008 is associated with three consecutive positive IOD events.

\section{Introduction}

During the last decade, large parts of Australia have suffered severe drought conditions, particularly in southern and eastern regions of the continent. The consequences are farreaching in their socioeconomic and environmental impacts, affecting water resources, agricultural productivity, and natural ecosystems (LeBlanc et al., 2009). Unusual hydrological conditions over the last decades across southern regions of Australia have been linked to a variety of factors, including large-scale pressure changes (e.g., Murphy and Timbal, 2008; Nicholls, 2009), higher air temperatures (e.g., Nicholls, 2004), Indian Ocean conditions (e.g., Cai et al., 2009a; Ummenhofer et al., 2009, 2011), and Pacific Ocean variability (e.g., Cai and Cowan, 2008), amongst others, with a combination of several factors most likely.

On interannual timescales, a considerable proportion of Australian climate variability is associated with variations in the dominant tropical modes of variability, namely the El Niño-Southern Oscillation (ENSO) and the Indian Ocean Dipole (IOD). Risbey et al. (2009) summarize the present understanding of the relative influence of these dominant climate drivers for Australian rainfall variations. During El Niño events, one of the phases of ENSO, a weakening or reversal of the Pacific trade winds is observed with a concurrent 
anomalous warming of the eastern and central Pacific equatorial waters. Large-scale circulation changes around the wider Pacific region ensue, with anomalous dry conditions dominating over Australia, particularly in the north and east (e.g., Ropelewski and Halpert, 1987). Broadly opposite climatic conditions across the Pacific region and Australia are observed during La Niña events. In the tropical Indian Ocean, the IOD is the complementary phenomenon to the Pacific's ENSO. During positive IOD events, anomalous cool (warm) waters appear in the eastern (western) Indian Ocean, associated with large-scale circulation changes that bring anomalous dry conditions to Indonesia, while East Africa experiences above-average rainfall (Saji et al., 1999; Webster et al., 1999). Australia experiences anomalous dry conditions during positive IOD events, while especially the south and east receive above-average rainfall during the opposite phase, the negative IOD events (Ummenhofer et al., 2009). Recently, the IOD has received increasing attention as being an important factor for prolonged drought conditions (Ummenhofer et al., 2009) and severe bushfire seasons (Cai et al., 2009b) in southeastern Australia, challenging the view that eastern Australian rainfall, and especially prolonged droughts, are predominantly associated with ENSO events.

The Gravity Recovery And Climate Experiment (GRACE) mission has been measuring time-variable gravity of the Earth on monthly averages since its launch in March 2002 (Tapley et al. 2004). Such gravity variations can be used to estimate statistically reliable water mass variations over Australia (Ellet et al., 2006), and then, they can be used to improve the hydrological models in the region (Ellet et al., 2005). Official releases of 
GRACE data contain some noise that must be filtered before use. The most common filter used by the GRACE community, due to its easy implementation, is the gaussian one (Jekeli, 1981; Swenson and Wahr, 2002), as done in previous studies about the Australian hydrology (Awange et al., 2009; Rieser et al., 2010). In this study, we apply a combination of two filters more appropriate than the gaussian one (Swenson and Wahr, 2006; Chen et al., 2006; Duan et al., 2008; Garcia-Garcia et al., 2010). Alternative approaches have also been explored in Australia (Leblanc et al., 2009; Awange et al., 2011), and surrounding seas (Tregoning et al., 2008).

Once GRACE data are filtered, we study annual and interannual water mass variations in Australia, focusing on the teleconnections of the interannual variations with the leading modes of Pacific and Indian Ocean variability, namely ENSO and IOD. While previous studies linked satellite-derived variations in Australian hydrology largely to ENSO variability (e.g., Liu et al., 2007), the present work focuses on associating remotely-sensed hydrological properties in Australia to Indian Ocean variability. Recent observed changes in Indian Ocean surface properties, including widespread non-uniform warming and changed frequency of IOD events (e.g., Abram et al., 2008; Ihara et al. 2008; Cai et al. 2009a), are likely to modulate regional circulation and rainfall variability. In light of these long-term changes and the importance of Indian Ocean variability for Australian rainfall across a range of timescales (e.g., Ummenhofer et al. 2011, and references therein), it is therefore of interest to assess the links between Australian water mass variations estimated from GRACE observations and Indian Ocean variability. 
The remainder of the study is structured as follows: Section 2 describes the processing of the time variable gravity data from GRACE. The results for seasonal and non-seasonal Australian water mass variations are presented in Section 3 and related to Indo-Pacific variability, followed by concluding remarks in Section 4.

\section{Data}

\subsection{ENSO and IOD indices}

The Southern Oscillation Index (SOI) is used as a measure for ENSO. It is based on the pressure difference between Tahiti and Darwin, as provided by the Australian Bureau of Meteorology. On the other hand, the Dipole Mode Index (DMI) is used as a measure for the IOD. The DMI is estimated as the difference between the western and the southeastern tropical Indian Ocean sea surface temperature (SST) indices, as described by Saji et al. (1999), by the Ocean Observations Panel for Climate from the UNESCO. Both indices are monthly and are normalized to 1-sigma standard deviation.

\subsection{Hydrology models}

(1) We use soil moisture from the Australian Water Availability Project (AWAP; Raupach et al., 2009; http://www.csiro.au/awap), which uses a simple dynamic water balance model driven by atmospheric forcing. AWAP soil moisture is a gridded product with a spatial 
resolution of $5 \mathrm{~km}$, spanning the period 01/2002 - 12/2008 at monthly resolution. Units are transferred to $\mathrm{mm}$ of water thickness equivalent (WTE), i.e., $\mathrm{kg} / \mathrm{m}^{2}$.

(2) We use surface water storage grids from GLDAS/Noah (Global Land Data Assimilation Systems) model (Rodell et al, 2004; http://disc.sci.gsfc.nasa.gov/hydrology/data-holdings). These grids are estimated from the integration of 4-layer soil moisture, snow equivalent height and canopy water. Data are monthly regular grids of $1^{\circ}$, with no data south of latitude $60^{\circ} \mathrm{S}$. The span of time is $01 / 2002-06 / 2010$, and the units are mm of WTE.

\subsection{Synthetic GRACE data}

The filtering process of GRACE data needs synthetic GRACE data, which are a modelization of the real GRACE measurements. The synthetic GRACE data basically are global grids with terrestrial water storage fields over land and with Ocean Bottom Pressure (OBP) over the oceans. The former is estimated from GLDAS/Noah model data, and the latter is estimated from the ECCO (Estimating the Circulation and Climate of the Ocean; Stammer et al., 2002; http://www.ecco-group.org/products.htm) model version kf080.

The synthetic GRACE data have been reduced to $1^{\circ} \times 1^{\circ}$ monthly grids for the period $01 / 2002-06 / 2010$, and transformed to mm of WTE. As we are interested in the variability of the data, the mean value for the period 2003-2009 is removed from the signal. The points covered neither by GLDAS/Noah nor ECCO are set to zero. Then, each monthly grid map is expanded into Spherical Harmonics (SH) coefficients [Heiskanen and Moritz, 1967],

obtaining $\Delta C_{n m}^{\text {synt }}(t)$ and $\Delta S_{n m}^{\text {syt }}(t)$, where t denotes the month. 


\subsection{Time-variable gravity data from GRACE}

In this study, Level-2 GRACE RL04 time variable gravity data from the Center of Space Research (CSR) are used (http://podaac-www.jpl.nasa.gov/grace/data_access.html\#Level2). Those data consists of 98 sets of fully normalized SH coefficients up to degree 60, which describe the monthly gravitational potential of the Earth from August 2002 to December 2010, with missing values in June 2003. The level-2 data are computed as gravity variations relative to those produced by some modeled geophysical phenomena, which have been removed from the processing of the data. So, if models were perfect, GRACE data would show no signals from secular trends in the $\mathrm{C}_{20}, \mathrm{C}_{30}, \mathrm{C}_{40}, \mathrm{C}_{21}$ and $\mathrm{S}_{21}$ coefficients, oceanic tides (including pole tide), non-tidal variability of the atmosphere and ocean, and gravity perturbations due to the Sun, Moon and the rest of the planets (Bettadpur, 2007).

We then process the data as follows: 1) Degree-1 SH coefficients, which are related to variations of the gravity center of the Earth, are zero in GRACE data by definition of the reference frame of the mission. So, the GRACE degree-1 coefficients are replaced by those based on the work of (Swenson et al., 2008); 2) The $\mathrm{C}_{20}$ coefficient is replaced by an estimate made from Satellite Laser Ranging (Cheng and Ries, 2007); 3) The linear trends of the $\mathrm{C}_{30}, \mathrm{C}_{40}, \mathrm{C}_{21}$ and $\mathrm{S}_{21}$ coefficients are restored. 4) As we are interested in water mass on land, we do not add the corrected atmospheric signal back in. As a consequence, errors in the atmospheric model (European Center for Medium Range Weather Forecast, ECMWF) may affect the land signals we seek; 5) As we are interested in the time variations of the gravity, we remove the mean geopotential for the period 2003-2009. 
From a theoretical point of view, if it is assumed that the variations of the geopotential are produced by changes of mass in the surface of the Earth, the latter can be estimated (Wahr et al., 1998, Chao, 2005). In the Earth and on monthly time scales, most of the mass variations are produced in the ocean, atmosphere and within a few meters in the surface of the continents, whose thickness is insignificant in relation to the radius of the Earth. This situation is not far from the theoretical assumption and then, surface mass variations can be estimated. However, high degree/order SH from GRACE are contaminated by noise, producing spurious North-South stripes in the surface mass global maps, and they must be filtered before inferring surface mass variations.

A 2-stage filter is then applied to reduce 'striping' and noise. The first stage reduces the correlated error in $\mathrm{SH}$ of even or odd degrees for a fixed order, which is related to the sampling along the polar orbit of the GRACE satellites (Swenson and Wahr, 2006). This filter is different for each month and depends on some parameters, which are fixed following Duan et al. (2008). This filter reduces the stripes, although the latter are still evident in low latitudes. Hence a second stage filter is applied. Usually, the chosen filter is the gaussian one (Jekeli, 1981; Swenson and Wahr, 2002), which is isotropic, that is, it depends on the degree but not on the order of the SH. The gaussian filter depends on one parameter, $r$, which is fixed following an error-proof procedure, just observing when the stripes (noise) disappear in the data. The advantage of this filter is that it can be easily implemented. Nevertheless, the noise in the GRACE SH is anisotropic, that is, it depends 
on both degree and order. Awange et al. (2009) applied the isotropic gaussian filter ( $r=500$ $\mathrm{km})$ to the RL02 and RL04 GRACE data from CSR in one single stage, and they highlighted the limitations of GRACE mission for reliably measuring the water budget variations in Australia. For that reason we use, in the second stage, the anisotropic filter from Chen et al. (2006), which is more appropriate than the Gaussian one.

The second stage filter needs the SH of synthetic GRACE data. Chen et al. (2006) presented two methods to estimate an anisotropic filter, namely Root Mean Squares and Formal Errors. We use the latter, but a modification is included in the input data. The filter is estimated as

$$
\begin{aligned}
& W_{n m}^{C}=\frac{R M S\left(\Delta C_{n m}^{s y n t}\right)^{2}}{R M S\left(\Delta C_{n m}^{s y n t}\right)^{2}+\left(S I G\left(\Delta C_{n m}^{G R A C E}\right)^{*} k\right)^{2}}, \\
& W_{n m}^{S}=\frac{R M S\left(\Delta S_{n m}^{s y n t}\right)^{2}}{R M S\left(\Delta S_{n m}^{s y n t}\right)^{2}+\left(S I G\left(\Delta S_{n m}^{G R A C E}\right)^{*} k\right)^{2}},
\end{aligned}
$$

where $W_{n m}^{C}$ and $W_{n m}^{S}$ are the weights to be used in the GRACE SH coefficients of degree $\mathrm{n}$ and order $\mathrm{m}, R M S\left(\Delta C_{n m}^{s y n t}\right)$ and $R M S\left(\Delta S_{n m}^{\text {synt }}\right)$ are the root mean square of the $\mathrm{SH}$ coefficients of the synthetic GRACE data, $\operatorname{SIG}\left(\Delta C_{n m}^{G R A C E}\right)$ and $\operatorname{SIG}\left(\triangle S_{n m}^{G R A C E}\right)$ are the reported formal errors of GRACE data, and $k$ is a parameter to be determined as explained below. The weights, $W_{n m}^{C}$ and $W_{n m}^{S}$, are fixed to one when the result of Eq. 1 is larger than one. 
The modification is that instead of the formal errors of GRACE data, we use an estimate as explained in Wahr et al. (2006). That is, each GRACE SH time series of any degree and order is fitted by a trigonometric polynomial with frequencies of $4,2,4 / 3,1,1 / 2$ and $161 / 365.25$ years. The latter frequency is to account for the aliasing produced by the under sampling in GRACE monthly data of the $\mathrm{K}_{2}$ ocean tides. Then, the fitted polynomial is subtracted from the original data and the residual is considered as an upper bound of GRACE errors, which is used in Eq. 1. It is obvious that the filter depends on both GRACE and synthetic GRACE data, and on the parameter $k$. Once estimated, the filter is not timedependent, but it is the same for any month. According to Chen et al. (2006), the parameter $k$ produces a filter that, once applied to GRACE data, maximizes the ratio of signal variance over continents relative to signal variance over oceans. When estimating the signal over the ocean, we do not consider the points closer than $750 \mathrm{~km}$ to the coast, in order to avoid land contamination. In this case a value of $k=0.8$ is obtained, and the weights of the SH ( $W_{n m}^{C}$ and $W_{n m}^{S}$ ), which is the filter itself, are estimated. Chen et al. (2006) found a value of $k$ larger than 1 , because they used an underestimation of the errors, and we found a value smaller than 1 because we used an upper bound. Then, the SH GRACE data are filtered and converted into grids of $1^{\circ} \times 1^{\circ}$ of surface mass variations (Wahr et al., 1998, Chao, 2005). Units are mm of WTE.

It is important to point out that the use of the models in setting up this filter does not force the filtered signal to look like either model, except in a statistical sense. Specifically, the 
power spectrum of the resultant fields (degree variances) is comparable to that of the models, but the phases are not, thus the spatial distribution of signals is not. Since the filter is not time-varying, it does not affect time variability of the signal.

Filtering GRACE data produces a loss of amplitude that should be restored. In order to estimate the restoring amplitude factor, the 2-stage anisotropic filter was applied to the synthetic GRACE data. Then, for every grid point, the corresponding time series was multiplied by a factor to minimize the root mean square of the residual with the non-filtered time series. Those factors (one for each grid point) are the sought restoring factors. So, the lost amplitude in GRACE data during the filtering process is restored multiplying the time series of each surface mass grid point by the corresponding factor (Swenson, S., "Restoring signal lost in GRACE terrestrial water storage estimates", manuscript in preparation). The averaged factor over Australia is 1.3, which is similar to the value of 1.5 obtained following the methodology explained in Velicogna and Wahr (2006). The latter accounts for the amplitude reduction of a uniform grid with ones in Australia and zeros otherwise, when the filter is applied.

\subsection{Other data sets}

A series of other data sets have been used as follows: (1) SST taken from HadISST by the UK Met Office (Rayner et al., 2003); (2) Moisture flux, calculated as the product of winds and specific humidity, vertically integrated below $500 \mathrm{hPa}$. The wind and humidity data are from the National Center for Environmental Prediction (NCEP) and the National Center for 
Atmospheric Research (NCAR; Kalnay et al., 1996); (3) Rainfall data over Australia based on a gridded product with a spatial resolution of 5km (Jones et al. 2009); (4) Precipitation minus Evaporation (P-E) from ERA-Interim reanalysis by ECMWF. Data sets (1), (2) and (3) span the period 1960 to 2009, while (4) is used for the period 1989 to 2010. All datasets are reanalysis products at monthly (or reduced to monthly) resolution.

\section{Results and discussion}

\subsection{Seasonal water mass variations}

A Complex Empirical Orthogonal Function (CEOF) analysis has been applied to the water mass grids derived from filtered GRACE data (Preisendorfer, 1988). Figure 1 shows the first mode, which explains $61 \%$ of the total variance. The spatial pattern and the associated time series are complex numbers, and both are represented by their corresponding amplitudes and phases. The amplitude of the spatial pattern shows maximum signal in the north and the weakest in the central band (Figure 1a; white regions have null amplitude, which means no variation in this mode). For each grid point, the signal is annual, which is inferred from the straight line decreasing 360 degrees every year in Figure 1d. The latter is zero at the beginning of the year, so the phase map in Figure $1 \mathrm{~b}$ shows when the annual maximum is reached (each degree represents $\sim 1$ day). Figure $1 \mathrm{~b}$ shows a propagation of the annual signal from the north to the south-east, reaching maxima in March north of $17.5^{\circ} \mathrm{S}$, and in October south of $35^{\circ} \mathrm{S}$. This is the reason why we use CEOF instead of non-complex 
EOF, since the latter analysis would not have shown this propagation. In particular, this CEOF mode would have been shown as 2 consecutive non-complex EOF modes with the respective annual signals out-of-phase around 3 months (Rieser et al. 2010).

The reported annual signal is related to the seasonal rainfall distribution: (1) The monsoonal high-rainfall region during austral summer (December-February) in the north; (2) Southern regions receive most of their rainfall during the cool season (June-October); (3) The interior is largely arid and therefore has very little amplitude; (4) The low amplitude along the eastern coast reflects the region's largely uniform rainfall throughout the year. Figure 1c shows the amplitude of the associated time series, which represents the modulation of the range of the annual signals (the first and last 4 months were removed as they contain artifacts due to tapering before taking the Fourier transform inherent in the CEOF). It has a mean value of $61 \mathrm{~mm}$ and exhibits a clear annual signal, with maxima occurring early in the year coincident with the austral summer monsoon in the north. Distinct maxima in early 2004, 2006 and 2009 reflect the anomalously strong monsoon seasons, while 2005, 2007 and 2008 recorded anomalous low monsoonal rainfall. The minima in the second half of 2006 are most likely due to anomalous low rainfall over southeastern Australia. The cause for these anomalies will be explored in more detail in the next section.

In order to verify this annual signal, the same CEOF analysis was applied to the GRACE JPL (Jet Propulsion Laboratory) mascons (mass concentration), to the soil moisture from 
AWAP, and to the surface water from the GLDAS/Noah model. The first CEOF mode of GRACE JPL, AWAP and GLDAS explains $48 \%, 47 \%$ and $58 \%$ of the variance, respectively. The latter is very close to the $61 \%$ of the first mode of the GRACE filtered data. All of them show the same annual signal with minimal differences (Figures 2, 3, and 4): (1) The AWAP and GLDAS amplitude maps show no signal in the central part of Australia; (2) The AWAP and GLDAS amplitude time series mean values are 127 and 50 $\mathrm{mm}$, respectively, while it is $61 \mathrm{~mm}$ in GRACE. The variations in the time series are comparable to the results described in Figure 1; (3) The propagating signal is not so evident in AWAP and GLDAS, although the $~ 6$-month delay between the north and the southeast due to the predominant rainfall season is also observed. Despite these differences, the agreement with GRACE data is remarkable, keeping in mind that all data sets are independent, except for the mascon and the SH GRACE data. Of course, these datasets are not perfectly comparable since they have been processed with different techniques and background assumptions. However, as all of them show the same signal, the signal cannot be a GRACE artifact. Besides, the reported percentages are similar to those from the first non-complex EOF mode of similar datasets estimated by Awange et al. (2011) for a shorter period of time. It is important to remind the reader that the second filter is independent of time, as explained above.

Then, the first CEOF mode of all datasets shows the same annual (seasonal) signal with the same modulation of the annual signal. Interannual variations in Australian rainfall, and hence water mass variations, are intricately linked to tropical ocean-atmosphere variability 
associated with ENSO and the IOD. Figure 1c shows the modulation of the range of the annual signal, as well as the SOI (as a measure for ENSO) and the DMI (as a measure for the IOD). In particular, the modulation of the range of the annual signal closely follows the SOI for the Period 1, which spans from 2003 to 2006, and from 2009 to mid-2010 (Figure 1c), but disappears for the Period 2 (2007-2008). In the first case (Period 1), there is a significant correlation of 0.80 at a 0.05 significance level, while in the 2007-2008 period there is no significant correlation (note that results in this period must be interpreted carefully due to the short time span). Previous studies with shorter time series also reported a low annual amplitude in 2005 from a non-complex EOF analysis of GRACE data in Australia (Rieser et al. 2010; Awange et al., 2011). However, the CEOF analysis allows the teleconnection of such anomaly with the SOI. Similarly, Liu et al. (2007), using satellitederived soil moisture for the period 1998-2005, linked soil moisture reductions and drought conditions post-2000 across eastern Australia, in particular for the Murray-Darling Basin, with El Niño conditions. In contrast, Ummenhofer et al. (2009) showed that prolonged drought conditions in southeastern Australia were more robustly linked to Indian Ocean, rather than Pacific conditions: negative IOD events are associated with above-average precipitation in the south and west of Australia, while below-average precipitation occurs during positive IOD events. During prolonged droughts over the last 100 years, a conspicuous absence of negative IOD events was identified as the main cause of multi-year droughts in southeastern Australia (south of $35^{\circ} \mathrm{S}$ ), depriving the region of its normal rainfall quota (Ummenhofer et al., 2009). From mid-2006 onwards, the IOD, represented by the DMI, consistently showed anomalous high values (Figure 1c; note that - DMI is 
shown and they appears as minima), which was associated with the unusual three consecutive positive IOD years 2006-2008. During the positive IOD years, the -DMI closely agrees with the modulation of the range of the annual water mass signal over Australia (Figure 1c). In particular, during the period with values of -DMI lower than -1, that is from mid-2006 to 2008, both curves show a significant correlation coefficient of 0.65 at a significance level of 0.05 (note that the correlation with DMI is -0.65 ). In contrast, protracted La Niña conditions, as reflected in the high SOI values post-2007 (Figure 1c), generally are expected to result in enhanced rainfall across eastern Australia. However, GRACE data over Australia post-2006 do not match ENSO variations as reflected by the SOI (Figure 1c). This is in agreement with Gallant and Karoly (2009), who reported that in 2007 southeastern Australia experienced rainfall and temperature conditions very unusual for a La Niña event and that the influence of the positive IOD event dominated throughout the period, as can be seen here in the GRACE data.

Note that large (small) values of the modulation of the range of the seasonal signal do not mean large (small) amounts of water, since, in the simplest case of a constant annual range, the signal would alternate between maxima and minima. Note also that north of $17^{\circ} \mathrm{S}$ and the southeast Australian (south of $35^{\circ} \mathrm{S}$; hereafter SEA) region show seasonal maxima in March and September, respectively (see Figure 1b). However, in spite of this out-of-phase behavior, both regions show the same variation in the modulation of the seasonal signal, which is influenced by both ENSO and IOD. Regarding the non-seasonal water mass 
variations, the connections with ENSO and IOD is quite different and will be explored with a focus on SEA.

3.2 Non-seasonal water mass variations and IOD

Mean annual and semi-annual sinusoids are estimated for the GRACE-derived water mass variation data by least-squares fitting. In this section, we will call the residual the 'non seasonal' signal obtained by subtracting the fitted signal from the original data. Figure 5a shows the correlation coefficient between the non-seasonal signal and the DMI. A significant negative correlation of up to -0.6 and around -0.5 (p-value $=0.05$ ) can be observed in SEA and parts of central and eastern Australia, respectively, which means that a negative (positive) phase of IOD increases (decreases) their water budget. This result is in agreement with the non-uniform response of Australian rainfall to IOD phases reported by Ummenhofer et al. (2009). To further confirm this result, we focus on the three consecutive maxima of the DMI in 2006, 2007 and 2008 (note that they appear as three minima, lower than -1 , in Figure 1c because -DMI is shown). So, the non-seasonal GRACE water mass data are averaged for the months around the maxima, that is June-October of the cited three years. Figure $5 \mathrm{~b}$ shows the water mass anomalies significant at the 0.05 level of the averaged data with respect to the 2003-2008 period. A below-average water budget is observed in central and southern Australia, and higher than normal locally in the north and northeast. 
In order to explore the climatic conditions characteristic of positive IOD events, we present in Figure 6 the composite anomalies based on the months June-October for the period 1960-2009 for those years defined as positive IOD events in Ummenhofer et al. (2009). To determine the significance of spatial anomaly fields of SST, vertically integrated moisture flux, and rainfall, a two-tailed t-test is used. At each grid point, the test provides a measure of statistical significance, at which the composite mean during the three consecutive positive IOD events is distinguishable from the mean of all years (1960-2009). The rainfall pattern (Figure 6c) is very similar to the water mass anomalies shown in Figure 5b. Differences between them can be due to the fact that GRACE does not measure precipitation, but its vertically- and time-integrated water storage, and includes evaporation and runoff. Decreases in the SEA water mass balance during the positive IOD events 20062008 can be understood to be due to below-average rainfall associated with a reduction of tropical moisture influx (Figures 5 and 6b). A positive correlation, with values around 0.3, is observed in Figure 5a in the north and northeast. However, it is not supported by an anomalously higher water budget in Figure 5b, and then, the influence of the IOD in this area is not so evident. Ummenhofer et al. (2011) showed that the influence of Indian Ocean temperatures, when they do not coincide with anomalous Pacific Ocean conditions associated with ENSO, on precipitation and soil moisture is restricted more locally to SEA only. This is in contrast to the more widespread dry (wet) conditions across Australia experienced during concurrent positive IOD and El Niño (negative IOD and La Niña) events. 
The water budget in Australia varies vertically through precipitation and evaporation, and horizontally via river runoff and underground water exchange with the ocean. The net result of all these water fluxes can be obtained from the time derivative of GRACE water mass variations. The latter has been estimated for SEA and shows a dramatic drop in 2006, which agrees well with a corresponding signal in the DMI (see Figure 7, where all curves are smoothed with a 12-month moving window and normalized to 1-sigma standard deviation; note that -DMI is shown). However, the curves show a mismatch in 2003 and 2007. In order to clarify this, we estimate the net water flux back to 1989 as the time derivative of the AWAP soil moisture. Figure 7 shows its non-seasonal average over SEA, which agrees quite well with the GRACE-derived flux (correlation coefficient of 0.67, pvalue $=0.05$ ). When comparing the former and the - DMI the agreement is not so good. However, -DMI reaches three maxima in 1992, 1996 and 1998, and three minima in 1994, 1997 and 2006/2007, all of them over 1-sigma distance from zero, that agree with maxima and minima of the AWAP-derived flux (note that the opposite is not always true). The IOD can thus be associated with most of the extreme conditions of the water mass fluxes in SEA over the last two decades.

For further validation of the results, the vertical exchange of water in Australia, that is P-E, is estimated in SEA. Figure 7 shows the non-seasonal averaged time series over SEA, which agrees quite well, except for decadal variability and mean value, with the water mass fluxes estimated from GRACE and AWAP data (correlation coefficient of 0.62, pvalue $=0.05)$ 


\section{Conclusions}

A 2-stage anisotropic filter has been applied to GRACE data to estimate water mass variations in Australia. About $61 \%$ of the variance of the latter is produced by an inhomogeneous and amplitude modulated seasonal signal. The signal is larger in the north and propagates from the north to the southeast with a 6-7 months delay, reflective of the predominant seasonality in precipitation. Thanks to a CEOF analysis it has been observed that the range of the seasonal signal is time variable and depends on both ENSO and IOD. In particular, a lowered range of the annual water mass signal is apparent during the three consecutive positive IOD events in 2006-2008, associated with a reduction of tropical moisture influx and reduced rainfall. The signal has been confirmed with GRACE mascons from JPL, with AWAP data, and with the GLDAS hydrological model. The Southern Annular Mode is another important climate driver in southern Australia, whose influence, in conjunction with ENSO and IOD, should be studied in future studies in the region.

The non-seasonal water mass variations are related to the IOD, especially in central and southeast Australia. These regions experience a lower than average water budget during positive IOD events. This variation is produced via changes of the P-E patterns and associated anomalous moisture flux. An extension back to 1989 with a hydrological model shows that over the last two decades three maxima of water mass fluxes (in 1992, 1996 and 
1998), and three minima (in 1994, 1997 and 2006/2007) in SEA coincided with anomalous excursions in the DMI as a measure of the IOD.

\section{Acknowledgments}

We thank F.W. Landerer for GRACE data processing support, and all the organizations providing the used data: time variable gravity data provided by the GRACE team; GLDAS hydrological data by GSFC/NASA; ocean bottom pressure by ECCO group; P-E data by ECMWF; HadISST from the Hadley Centre, UK Met Office; winds and specific humidity from the NCEP/NCAR reanalysis project provided by NOAA/OAR/ESRL PSD, Boulder, USA, through their website http://www.cdc.noaa.gov; SOI by the Australian Bureau of Meteorology, DMI by Ocean Observations Panel for Climate from the UNESCO, Australian rainfall and soil moisture from AWAP kindly provided by Peter Briggs. This work has been partly supported by a NASA GRACE Science Team grant, two Spanish Projects from MICIN, ESP2006-11357 and AYA2009-07981, one from Generalitat Valenciana, ACOMP2009/031, and one from the University of Alicante, GRE10-13. The third author acknowledges support from the GRACE Science Team; this work was performed, in part, at the Jet Propulsion Laboratory, California Institute of Technology, under contract with the National Aeronautics and Space Administration.

\section{References}


Abram, N. J., Gagan, M. K., Cole, J. E., Hantoro, W. S., \& Mudelsee, M. (2008). Recent intensification of tropical climate variability in the Indian Ocean. Nature Geoscience, doi:10.1038/ngeo357.

Awange, J.L., Sharifi, M.A., Baur, O., Keller, W., Featherstone, W.E., \& Kuhn, M. (2009). GRACE hydrological monitoring of Australia: current limitations and future prospects. Journal of Spatial Science 54 (1), 23-36.

Awange, J.L., Fleming, K.M., Kuhn, M., Featherstone, W.E., Heck, B., \& Anjasmara, I. (2011). On the suitability of the $4^{\circ} \times 4^{\circ}$ GRACE mascon solutions for remote sensing Australian hydrology. Remote Sensing of Environment, 115, 864-875, doi:10.1016/j.rse.2010.11.014.

Bettadpur, B. (2007). CSR Level-2 Processing Standards Document for Product Release 04 GRACE 327-742. (Available at http://podaac.jpl.nasa.gov/grace/documentation.html)

Cai, W., \& Cowan, T. (2008). Dynamics of late autumn rainfall reduction over southeastern Australia. Geophys. Res. Lett., 35, L09708, doi:10.1029/2008GL033727.

Cai, W., Cowan, T., \& Sullivan, A. (2009a). Recent unprecedented skewness towards positive Indian Ocean Dipole occurrences and their impact on Australian rainfall. Geophys. Res. Lett., 36, L11705, doi:10.1029/2009GL037604. 
Cai, W., Cowan, T., \& Raupach, M. (2009b). Positive Indian Ocean Dipole events precondition southeast Australia bushfires. Geophys. Res. Lett., 36, L19710, doi:10.1029/2009GL0399902.

Chao, B.F. (2005). On inversion for mass distribution from global (time-variable) gravity field. J. Geodyn., 39, 223 - 230, doi:10.1016/j.jog.2004.11.001.

Chen, J.L., Wilson, C. R., \& Seo, K.-W. (2006). Optimized smoothing of Gravity Recovery and Climate Experiment (GRACE) time-variable gravity observations. J. Geophys. Res., 111, B06408, doi:10.1029/2005JB004064.

Cheng, M., \& Ries, J. (2007). GRACE Technical Note \#05: Monthly estimates of C20 from 5 SLR satellites. (Available at http://podaac.jpl.nasa.gov/grace/documentation.html)

Duan, X. J., Guo, J. Y., Shum, C. K., \& van der Wal, W. (2009). On the postprocessing removal of correlated errors in GRACE temporal gravity field solutions. J. Geod. 83, 10951106, doi:0.1007/s00190-009-0327-0.

Ellett K. M., Walker, J. P., Rodell, M., Chen, J. \& Western, A. W. (2005). GRACE gravity fields as a new measure for assessing large-scale hydrological models. In: Argent R. \& Zerger A. eds. MODSIM 2005 International Congress on Modelling and Simulation. Modelling and Simulation Society of Australia and New Zealand, Canberra, 2911-2917. 
Ellett, K. M., Walker, J. P., Western, A. W. \& Rodell, M. (2006). A framework for assessing the potential of remote-sensed gravity to provide new insight on the hydrology of the Murray- Darling Basin. Australian Journal of Water Resources 10 (2), 125- 138.

Gallant, A. J. E., \& Karoly, D. J. (2009). Atypical influence of the 2007 La Niña on rainfall and temperature in southeastern Australia. Geophys. Res. Lett., 36, L14707, doi:10.1029/2009GL039026

Garcia-Garcia, D., Chao, B.F., \& Boy, J.-P. (2010). Steric and Mass-Induced Sea Level Variations in the Mediterranean Sea, Revisited. J. Geophys. Res., 115, C12016, doi:10.1029/2009JC005928..

Heiskanen, W. A., \& Moritz, H. (1967). Physical Geodesy. W. H. Freeman and Company, San Francisco and London.

Ihara, C., Y. Kushnir, \& Cane, M. A. (2008). Warming trend of the Indian Ocean SST and Indian Ocean Dipole from 1880 to 2004. J. Climate, 21, 2035-2046, doi:10.1175/2007JCLI1945.1.

Jekeli, C. (1981). Alternative methods to smooth the Earth's gravity field. Dep. of Geod. Sci. and Surv., Ohio State Univ., Columbus. 
Jones, D. A., Wang, W. \& Fawcett, R. (2009). High-quality spatial climate data-sets for Australia. Australian Meteorological and Oceanographic Journal, 58, 233-248.

Kalnay, E., et al. (1996). The NCEP/NCAR 40-year reanalysis project. Bull. Am. Met. Soc., $77,437-471$.

LeBlanc, M. J., Tregoning, P., Ramillien, G., Tweed, S. O., \& Fakes, A. (2009). Basinscale integrated observations of the early $21^{\text {st }}$ century multiyear drought in southeast Australia. Water Resources Research, 45, W04408, doi:10.1029/2008WR007333.

Liu, Y., de Jeu, R. A. M., van Dijk, A. I. J. M., \& Oew, M. (2007). TRMM-TMI satellite observed soil moisture and vegetation density (1998-2005) show strong connection with El Niño in eastern Australia. Geophys. Res. Lett., 34, L15401, doi:10.1029/2007GL030311

Murphy, B. F., \& Timbal, B. (2008). A review of recent climate variability and climate change in southeastern Australia. Internat. J. Climatol., 28, 859-879, doi:10.1002/joc.1627.

Nicholls, N. (2004). The changing nature of Australian droughts. Clim. Change, 63, 323 336, doi:10.1023/B:CLIM.0000018515.46344.6d.

Nicholls, N. (2009). Local and remote causes of the southern Australian autumn-winter rainfall decline, 1958-2007. Clim. Dyn., doi:10.1007/s00382-009-0527-6. 
Preisendorfer, R.W. (1988). Principal component analysis in Meteorology and Oceanography, Elsevier Sci., New York.

Raupach M. R., Briggs, P. R., Haverd, V., King, E. A., Paget, M., \& Trudinger, C. M. (2009). Australian Water Availability Project (AWAP): CSIRO Marine and Atmospheric Research Component: Final Report for Phase 3. CAWCR TechnicalReport No. 013, Canberra, Australia, 67 pp.

Rayner, N. A., Parker, D. E., Horton, E. B., Folland, C. K., Alexander, L. V., Rowell, D. P., Kent, E. C., \& Kaplan, A. (2003). Global analyses of sea surface temperature, sea ice, and night marine air temperature since the late nineteenth century, J. Geophys. Res., 108, D144407, doi:10.1029/2002JD002670.

Rieser, D., Kuhn, M., Pail, R., Anjasmara, I. M., \& Awange, J. (2010). Relation between GRACE-derived surface mass variations and precipitation over Australia. Australian Journal of Earth Sciences, 1440-0952, 57 (7), 887-900, doi:10.1080/08120099.2010.512645.

Risbey, J. S., Pook, M. J., McIntosh, P. C., Wheeler, M. C. \& Hendon, H. H. (2009). On the remote drivers of rainfall variability in Australia. Mon. Wea. Rev., 137, 3233-3253, doi:10.1175/2009MWR2861.1. 
Rodell, M., Houser, P. R., Jambor, U., Gottschalck, J., Mitchell, K., Meng, C.-J., Arsenault, K., Cosgrove, B., Radakovich, J., Bosilovich, M., Entin, J. K., Walker, J. P., Lohmann, D., \& Toll, D. (2004). The Global Land Data Assimilation System. Bull. Amer. Meteor. Soc., 85 (3), 381-394, doi:10.1029/2004GL020873.

Ropelewski, C.F., \& Halpert, M.S. (1987). Global and regional scale precipitation patterns associated with El Nino-Southern Oscillation. Mon. Wea. Rev., 137, 3233-3253

Saji, N. H., Goswami, B. N., Vinayachandran, P. N., \& Yamagata, T. (1999). A dipole mode in the tropical Indian Ocean. Nature, 401, 360-363, doi:10.1038/43854.

Stammer, D., Wunsch, C., Fukumori, I., \& Marshall, J. (2002). State estimation in modern oceanographic research. Eos, Trans. Amer. Geophys. Union, 83, 289, 294-295.

Swenson, S., \& Wahr, J. (2002). Methods for inferring regional surface mass anomalies from Gravity Recovery and Climate Experiment (GRACE) measurements of time-variable gravity. J. Geophys. Res., 107(B9), 2193, doi:10.1029/2001JB000576.

Swenson, S., \& Wahr, J. (2006). Post-processing removal of correlated errors in GRACE data. Geophys. Res. Lett., 33, L08402, doi:10.1029/2005GL025285. 
Swenson, S., Chambers, D., \& Wahr, J. (2008). Estimating geocenter variations from a combination of GRACE and ocean model output. J. Geophys. Res., 113, B08410, doi:10.1029/2007JB005338.

Tapley, B. D., Bettapdur, S., Ries, J. C., Thompson, P. F., \& Watkins, M. M. (2004). GRACE measurements of mass variability in the Earth system. Science, 305, 503- 505, doi: 10.1126/science.1099192.

Tregoning, P., Lambeck, K., \& Ramillien, G. (2008). GRACE estimates of sea surface height anomalies in the Gulf of Carpentaria, Australia. Earth Planet. Sci. Lett., 271, 241244, doi:10.1016/j.eps1.2008.04.018.

Ummenhofer, C. C., England, M. H., McIntosh, P. C., Meyers, G. A., Pook, M. J., Risbey, J. S., Gupta, A. S., \& Taschetto, A. S. (2009). What causes southeast Australia's worst droughts? Geophys. Res. Lett., 36, L04706, doi:10.1029/2008GL036801.

Ummenhofer C. C, Sen Gupta, A., Briggs, P. R., England, M. H., McIntosh, P. C., Meyers, G. A., Pook, M. J., Raupach, M. R., \& Risbey, J. S. (2011). Indian and Pacific Ocean influences on Southeast Australian drought and soil moisture. J. Climate, doi:10.1175/2010JCLI3475.1 
Velicogna, I., \& Wahr, J. (2006). Measurements of Time-Variable Gravity Show Mass Loss in Antarctica. Science, 311, 1754-1756, doi:10.1126/science.1123785.

Wahr, J., Molenaar, M., \& Bryan, F. (1998). Time variability of the Earth's gravity field: Hydrological and oceanic effects and their possible detection using GRACE. J. Geophys. Res., 103, 30,205-30,229.

Wahr, J., Swenson, S., \& Velicogna, I. (2006). Accuracy of GRACE mass estimates. Geophys. Res. Lett., 33, L06401, doi:10.1029/2005GL025305.

Webster, P. J., Moore, A. M., Loschnigg, J. P., \& Leben, R. R. (1999). Coupled oceanatmosphere dynamics in the Indian Ocean during 1997-98. Nature, 401, 356-360, doi:10.1038/43848. 


\section{Figures}
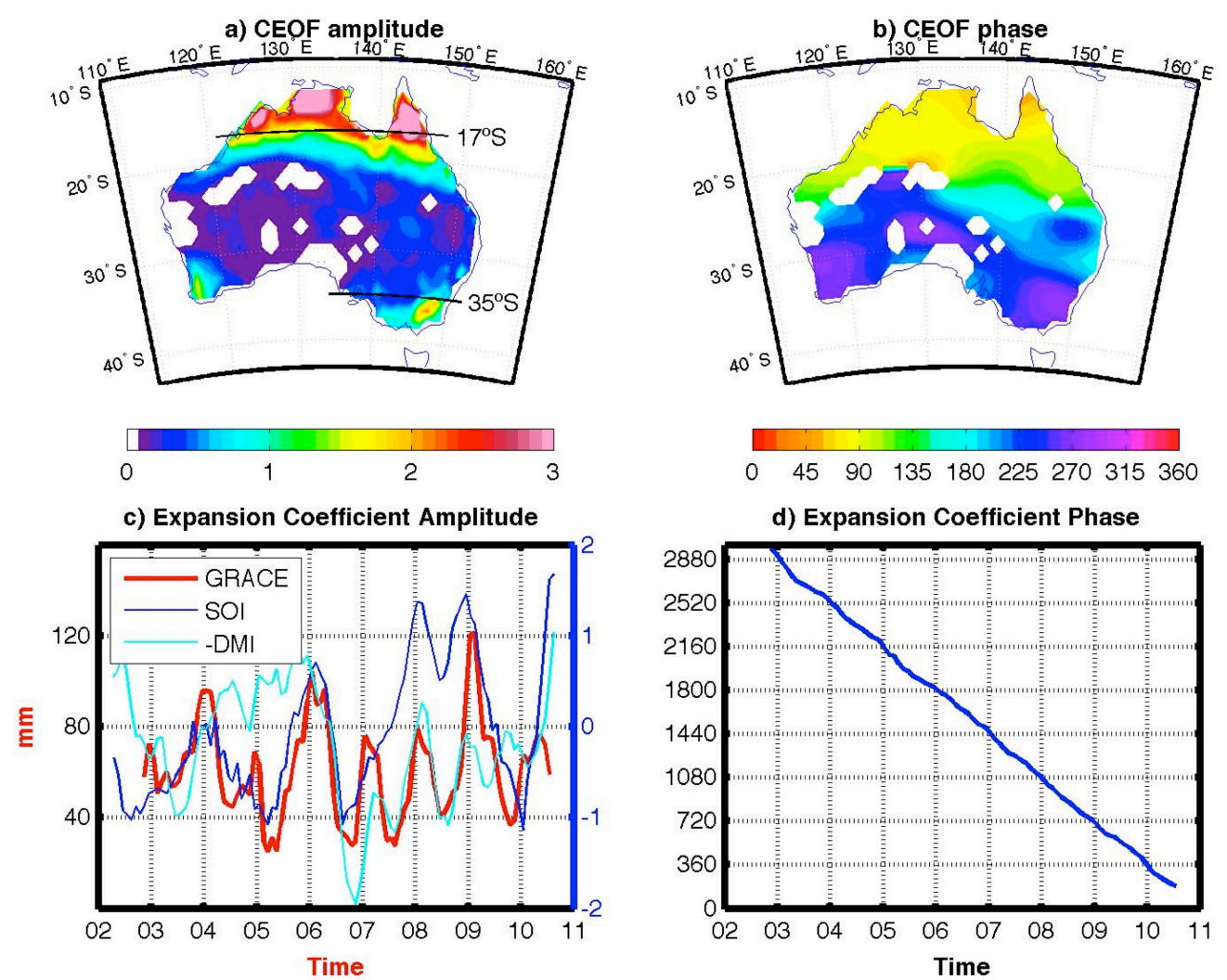

d) Expansion Coefficient Phase

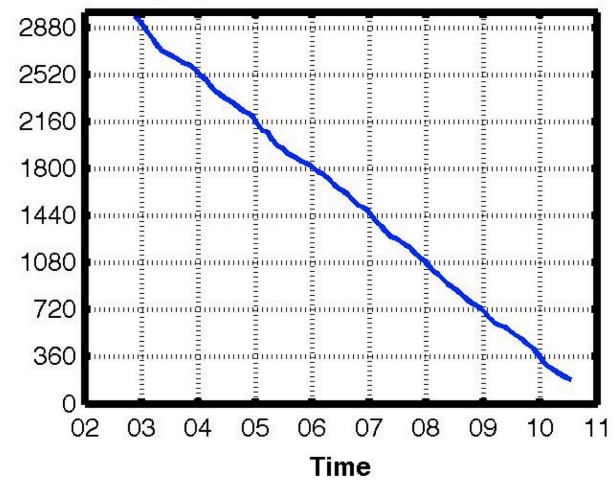

Figure 1. First CEOF of GRACE data, which explains $61 \%$ of the variance. a) Amplitude of the spatial pattern. White points are points with no signal in this mode; b) Phase of the spatial pattern; c) Red line: Amplitude of the associated time series (expansion coefficient); Blue line: SOI; Cyan line: -DMI (N.B.: for ease of comparison, the DMI has been multiplied with -1). Both indexes are 1-sigma normalized and averaged over 6-months moving windows; d) Phase of the associated time series. 
a) CEOF amplitude

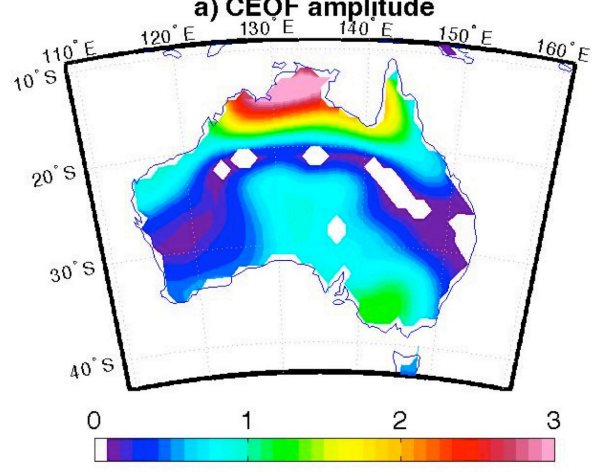

c) Expansion Coefficient Amplitude

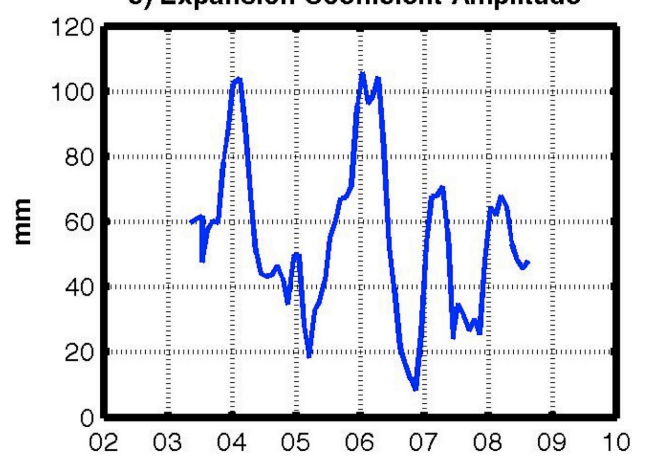

b) CEOF phąse

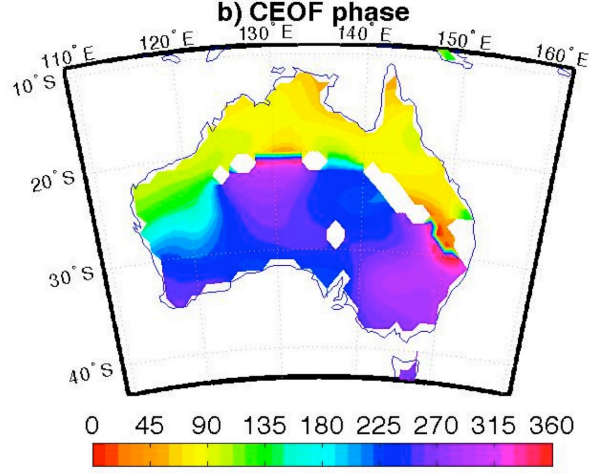

d) Expansion Coefficient Phase

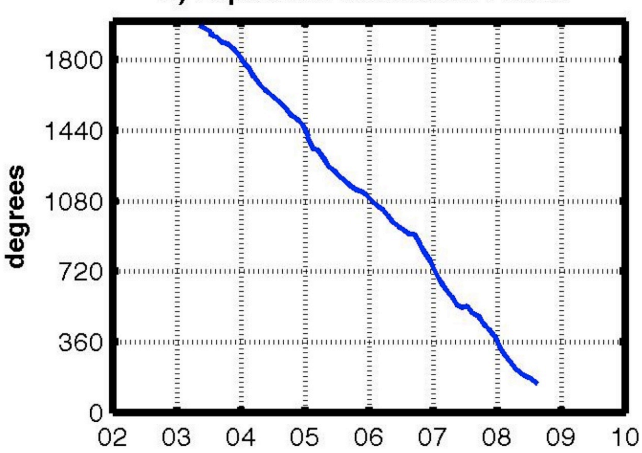

Figure 2. As Figure 1 but for GRACE JPL Mascons data. This mode explains $47.8 \%$ of the variance. 
a) CEOF amplitude

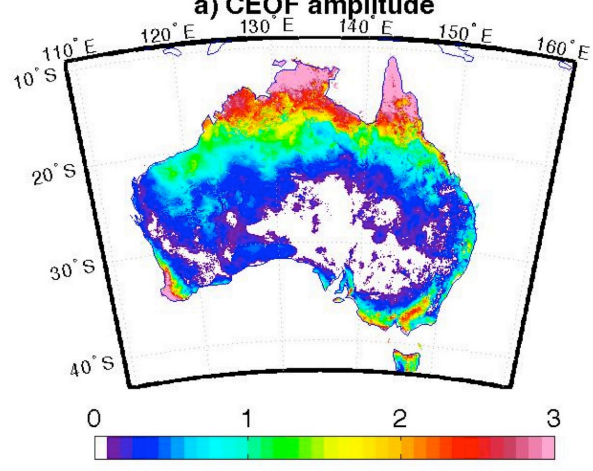

c) Expansion Coefficient Amplitude

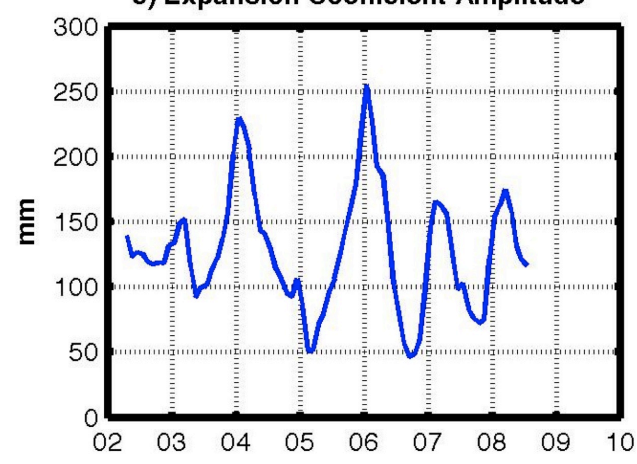

b) CEOF phąse

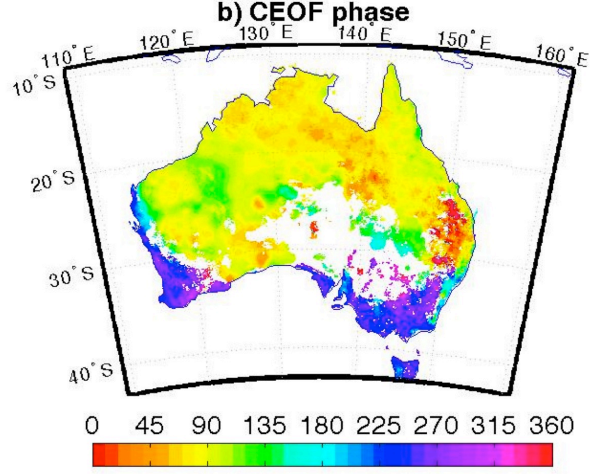

d) Expansion Coefficient Phase

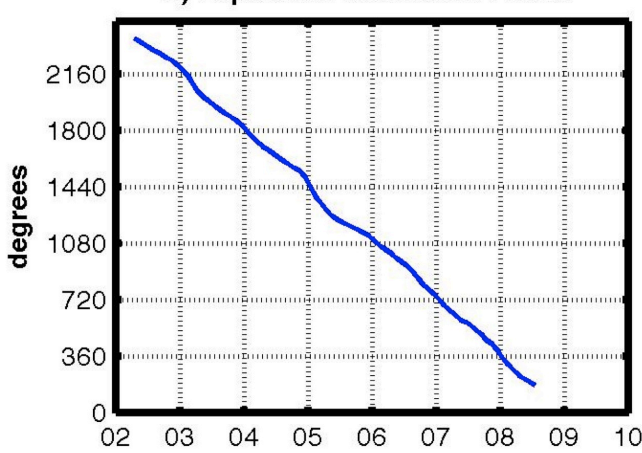

Figure 3. As Figure 1 but for AWAP data. This mode explains $46.6 \%$ of the variance. 
a) CEOF amplitude

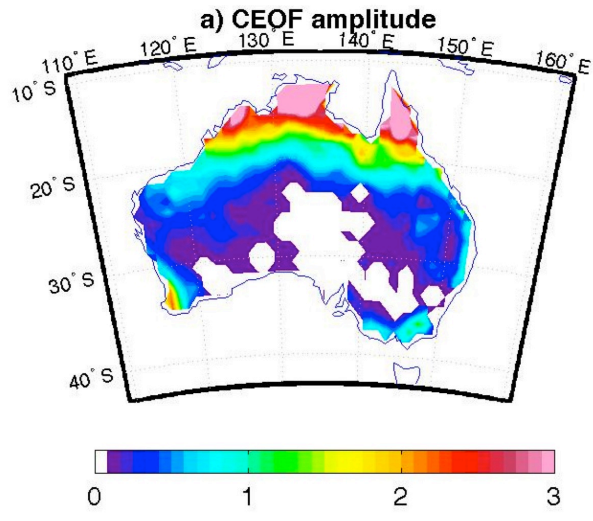

c) Expansion Coefficient Amplitude

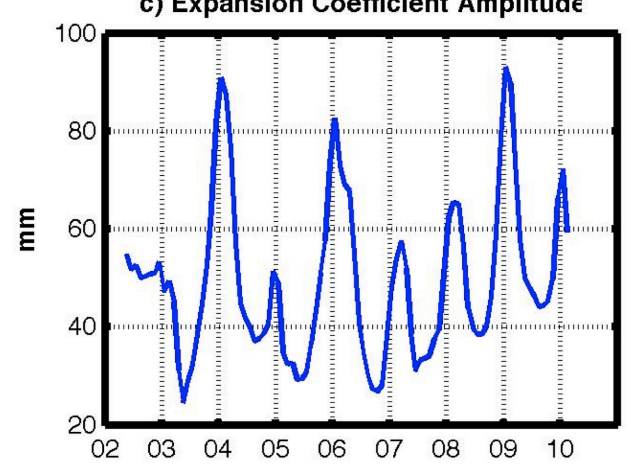

b) CEOF phase

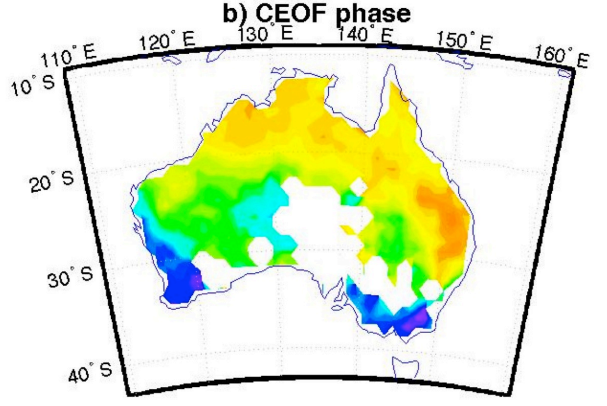

$0 \quad 45 \quad 90 \quad 135 \quad 180 \quad 225 \quad 270 \quad 315 \quad 360$

d) Expansion Coefficient Phase

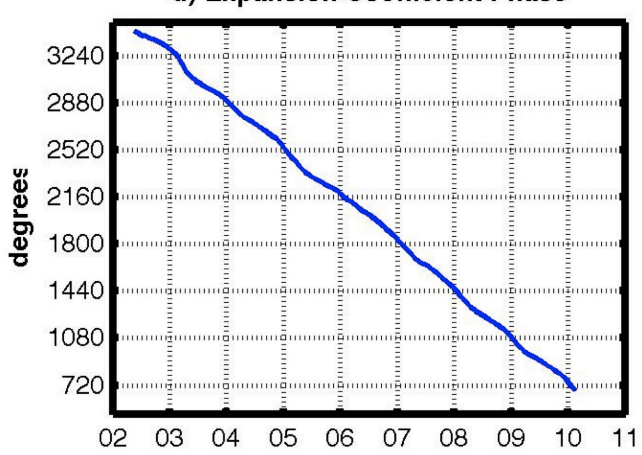

Figure 4. As Figure 1 but for GLDAS/Noah data. This mode explains 58\% of the variance. 

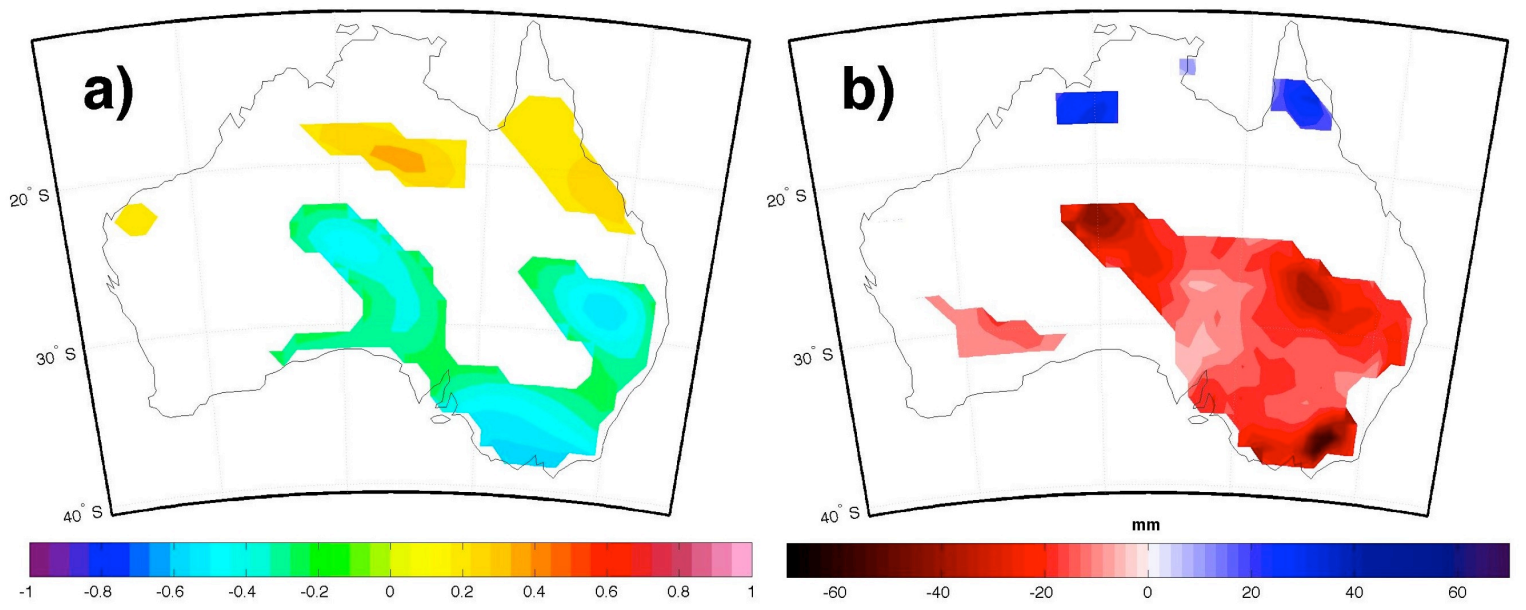

Figure 5. a) Correlation coefficient between the non-seasonal water mass budget from GRACE and the DMI. Both signals have previously been smoothed with a 6-months moving window; b) Anomalous non-seasonal water mass content from GRACE averaged over the months from June to October in 2006, 2007 and 2008, with respect to the mean of 2003-2008. Only points with a significant correlation or anomaly are represented (p-value $=$ $0.05)$. 

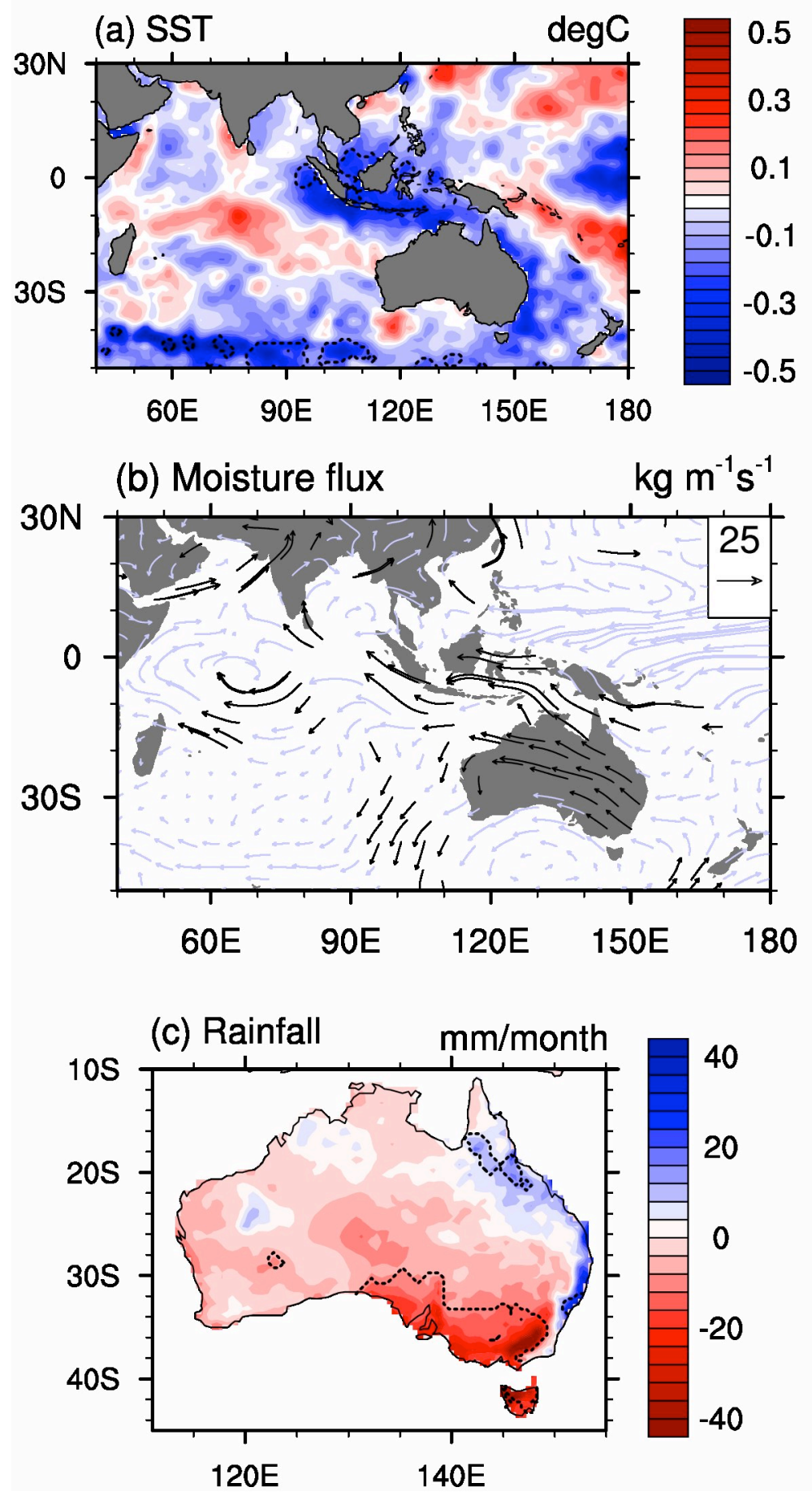

Figure 6. Anomalous (a) $\operatorname{SST}\left({ }^{\circ} \mathrm{C}\right)$, (b) moisture flux (vertically integrated below $500 \mathrm{hPa}$; $\left.\mathrm{kg} \mathrm{m}^{-1} \mathrm{~s}^{-1}\right)$, and (c) rainfall $\left(\mathrm{mm} \mathrm{month}{ }^{-1}\right.$ ) patterns averaged over the months June to 
October in 2006, 2007 and 2008, with respect to the period 1960-2009. Dashed contours and black vectors indicate anomalies significant at the $80 \%$ level, as determined by a twotailed $t$-test.

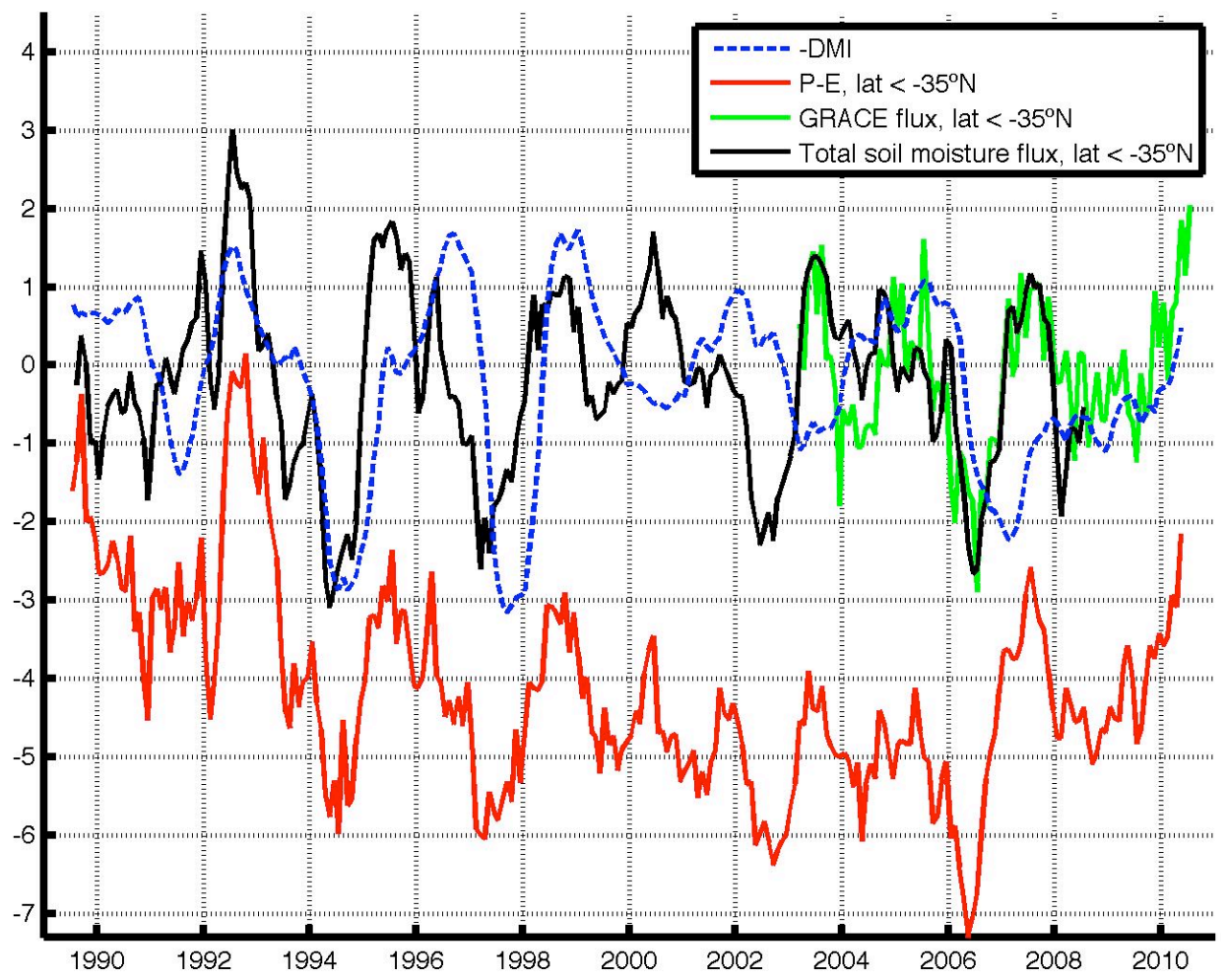

Figure 7. All curves are normalized to 1-sigma standard deviation, and smoothed with 12months moving windows. Solid lines are non-seasonal signals averaged over SEA. Blue dashed line: -DMI (N.B.: for ease of comparison the DMI has been multiplied with -1); Green line: water mass flux from GRACE; Black line: water mass flux from AWAP soil moisture data; Red line: P-E from ECMWF. 